DOI: https://doi.org/10.24867/16BE04Dimitrijevic

\title{
PROJEKTOVANJE SISTEMA ZA MERENJE SNAGE PODRŽANOG VIRTUELNOM INSTRUMENTACIJOM
}

\section{DESIGN OF A POWER MEASUREMENT SYSTEM SUPPORTED BY VIRTUAL INSTRUMENTATION}

\author{
Aleksandar Dimitrijević, Fakultet tehničkih nauka, Novi Sad
}

\begin{abstract}
Oblast - ELEKTROTEHNIKA I RAČUNARSTVO
Kratak sadržaj - U radu je prikazana praktična realizacija dodatne funkcije za merno-akvizicioni sistem (MAS) koja omogućava precizno merenje snage uz pomoć CompactDAQ platforme i LabVIEW razvojnog okruženja. $U$ radu je prikazan način rada modula potrebnih za realizaciju navedene funkcije, njihova međusobna sinhronizacija, deteljna analiza $i$ objašnjenje rezultata merenja, kao $i$ softverski način proračuna snage $i$ kompenzacije transportnog kašnjenja koja je posledica nesavršenosti prilagodnika signala. Takođe, prikazan je kratak opis mernih kanala MAS-a i instrumentacije.
\end{abstract}

Ključne reči: merenje snage, sinhronizacija, mernoakvizicioni sistem, transporno kašnjenje

\begin{abstract}
It is presented and practically implemented in the paper an additional function for the measurement and acquisition system. This function allows the precise measurement of the power using the CompactDAQ platform and LabVIEW development environment. It is presented in the paper the work methods for every module, which was used for implementation of this function, their mutual synchronization, detailed analysis and measurement, as well as software calculations of power, and compensation of the transport delay which is a consequence of the imperfection of signal conditioners. Also, it is presented the short description of measurement channels and instrumentation.
\end{abstract}

Keywords power measurement, synchronization, measurement and acquisition system, transport delay

\section{UVOD}

Merenje električne snage, sa aspekta energetike, predstavlja jedno od bitnijih merenja čiji rezultat korisniku omogućava pregled trenutnog stanja posmatranog sistema.

Precizno merenje snage je jedan od zahteva pri projektovanju takvih sistema.

Ideja za izdradu ovog rada, proistekla je iz potrebe da se na već postojećem merno-akvizicionom sistemu (MAS)

koji je razvio Elektrotehnički institut Nikola Tesla a.d Beograd implementira funkcija za precizno merenje snage. Implementacijom funkcije preciznog merenja snage, unapređuje se već postojeća multifunkcionalnost

\section{NAPOMENA:}

Ovaj rad proistekao je iz master rada čiji mentor je bio dr Platon Sovilj, red. prof.
$M A S$ - $a$, ubrzava se i olakšava postupak merenja, isključuje se potreba za primenu drugih, posebnih instrumenata za merenje snage.

\section{OPIS HARDVERA}

$M A S$ se sastoji od šasije sa mernim i izlaznim karticama, priključnih klema, napajanja, prilagodnika signala $\mathrm{i}$ izbornika koji su međusobno povezani i postavljeni u isto kućište. Šasija i merne kartice su proizvodnje National Instruments (NI)

\section{1. cDAQ-9178}

Šasija $c D A Q-9178$ [1] je šasija koja je dizajnirana za male, prenosne merne i simulacione sisteme. Ima mogućnost plug-and-play-a, odnosno mogućnost jednostavne izmene konfiguracije sistema vađenjem jedne $\mathrm{i} / \mathrm{ili}$ ubacivanjem druge kartice. Za rad koristi $I / O$ module $C$ serije kojima se mogu kreirati različite kombinacije analognih $I / O$ modula, digitalnih $I / O$ modula kao i brojača/tajmera. Komunikaciju sa računarom izvršava putem USB porta. Izgled šasije bez umetnutih kartica prikazan je na sl.l.

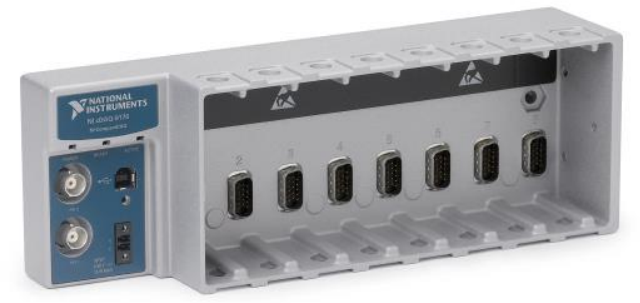

Slika 1: Izgled cDAQ-9178 šasije

\subsection{NI 9203 DAQ kartica}

Analogne ulazne kartice $C$ serije za NI CompactDAQ i CompactRIO platforme pružaju podršku visoko performansnim merenjima za široki spektar industrijskih, automobilskih i laboratorijskih senzora. U svaku karticu ugrađen je interni prilagodnik signala i priključnica za lako pričvršćivanje provodnika.

Modul NI-9203 [2] je merna kartica $C$ serije sa 8 analognih ulaznih kanala namenjen za aplikacije kontrole i nadzora visokih performansi. Ima mogućnost programabilnih ulaznih opsega. Bipolarni opseg $\pm 20 \mathrm{~mA}$ i unipolarni od 0 do $20 \mathrm{~mA}$. Poseduje jedan 16-bitni A/D konvertor. Maksimalna brzina uzorkovanja je $200 \mathrm{kS} / \mathrm{s}$. Izgled kartice prikazan je na sl.2. 


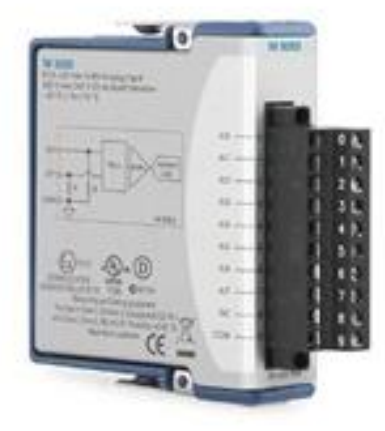

Slika 2: Izgled NI-9203 merene kartice

Tokom izrade ovog rada, primenom merne kartice ovog tipa merili su se naponi i struje trofaznog sistema uz primenu dodatnih eksternih prilagodnika signala. Na sl. 3 . prikazana je šema merne kartice NI-9203.

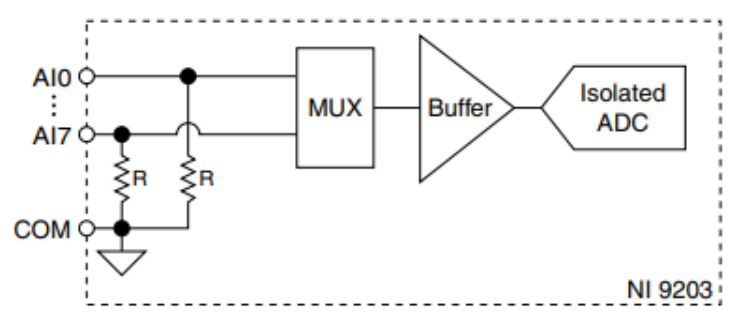

Slika 3: Šematski prikaz NI-9203 merne kartice

Svaki signal doveden na karticu može biti povezan na dva načina:

- Povezivanje ulaza u odnosu na zajedničku tačku (AI0-COM)

- Diferencijalno povezivanje (AI0-AI1)

\section{KORIŠĆENI UREĐAJI I MERILA}

Kao simulator trofaznog sistema korišćen je trofazni izvor struja i napona promenljive amplitude, učestanosti i faze RETOM-51 [3]. Za određivanje kašnjenja signala na eksternim prilagodnicima signala korišćen je osciloskop FLUKE 190-102 [4] dok je za precizno merenje snage korišćen precizni mrežni analizator ZES ZIMMER LMG640 [5].

\subsection{FLUKE 190-102 osciloskop}

FLUKE 190-102 je dvokanalni osciloskop sa sigurnosnom ocenom CAT III 1000V/CAT IV 600V, koga odlikuju visoke performanse od kojih izdvajamo:

- Propusni opseg od $100 \mathrm{MHz}$

- Odbirkovanje u realnom vremenu brzine do $1.25 \mathrm{GS} / \mathrm{s}$

- Model poseduje memorijski prostor koji čuva do 10000 semplova po kanalu čime omogućava detaljnu analizu svakog dela signala Izgled uređaja prikazan je na sl.4.

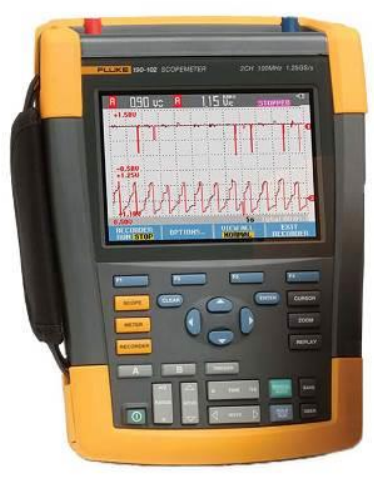

Slika 4: Osciloskop FLUKE 190-102

\subsection{RETOM-51}

RETOM-51 je programabilni uređaj za simulaciju naponskih i strujnih signala.

Izgled uređaja prikazan je na slici 5.

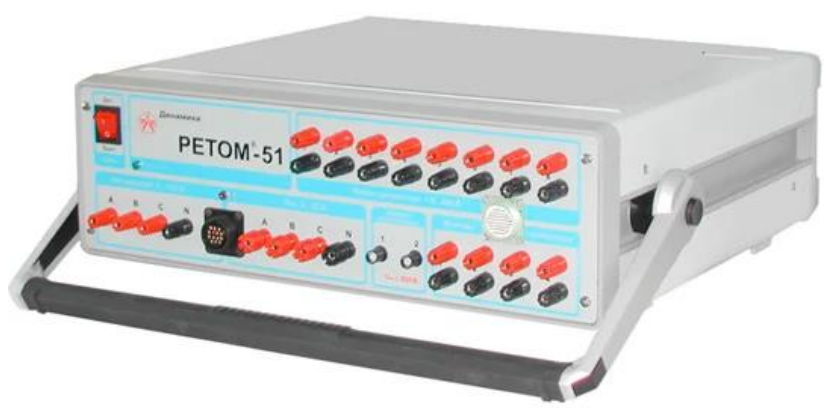

Slika 5: RETOM-51

RETOM-51 može da generiše prostoperiodične signale efektivne vrednosti napona do $120 \mathrm{~V}$ i struja do $20 \mathrm{~A}$, u trofasnom rasporedu.

\subsection{ZES ZIMMER LMG640 precizni analizator snage}

LMG640 je uređaj za merenje snage i kvaliteta električne energeije. $\mathrm{U}$ ovom radu upotrebljen je u svrhu kontrolnog merenja za verifikaciju projektovanog sistema. Neke od njegovih osobina su:

- Tačnost od $0,015 \%$ izmerene vrednosti $+0,01 \%$ od opsega

- Puni dinamički opseg struje od $500 \mu \mathrm{A}$ do $21 \mathrm{~A} \mathrm{i}$ napona od $3 \mathrm{mV}$ do $1000 \mathrm{~V}$ po kanalu

- Analogni propusni opseg DC do 10Mhz

- Modularna konfiguracija sa 1 do 4 katala za marenje snage

- Uzorkovanje bez greške do 18 bita i vreme ciklusa od 30ms

- Kašnjenje između naponskog i strujnog ulaza $<3$ ns, vrlo precizna merenja pri malim faktorima snage ili/i visokim frekvencijama

Izgled uređaja prikazan je na slici 6 . 


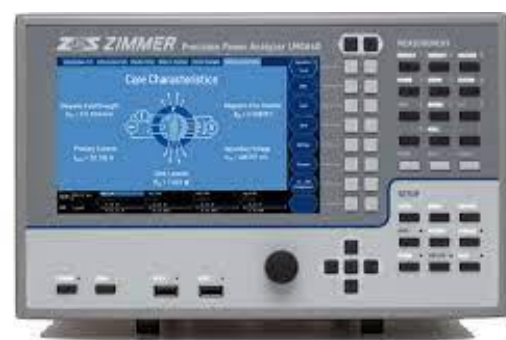

Slika 6: ZES ZIMMER LMG640

\section{KORIŠĆENI SOFTVER}

Tokom izrade rada za upotrebu sa CompactDAQ platformom, korišćeno je LabVIEW razvojno okruženje proizvođača $N I$. Ovo razvojno okruženje zasnovano je na vizuelnom programiranju što omogućava korisniku da relativno brzo napreduje u projektovanju željene aplikacije.

Najčešće primene LabVIEW-a su u izradi sistema za akviziciju, upravljanje instrumentacijom, automatizaciju ispitivanja, analizu i procesiranje signala, industrijsku kontrolu procesa, izradu embeded sistema i dr.

\section{SINHRONIZACIJA IZMEĐU MODULA}

Prvi korak ka realizaciji rada je bila sinhronizacija dve merne kartice tipa NI-9203. Prva tri kanala jedne merne kartice bila su namenjena za merenje napona dok su prva tri kanala druge merne kartice bila namenjena za merenje struja trofaznog sistema.

Kartice se povezuju na šasiju $c D A Q-9178$ čiji je zadatak da podatke preuzete sa kartica prosledi ka računaru.

Kako bi se dobio efekat istovremenosti u očitavanju multipleksera svake od kartica neophodno je proslediti isti sinhronizacioni signal svakoj kartici. Na sl.7. prikazan je deo koda koji prikazuje jedan od načina na koji se moduli mogu sinhronizovati.

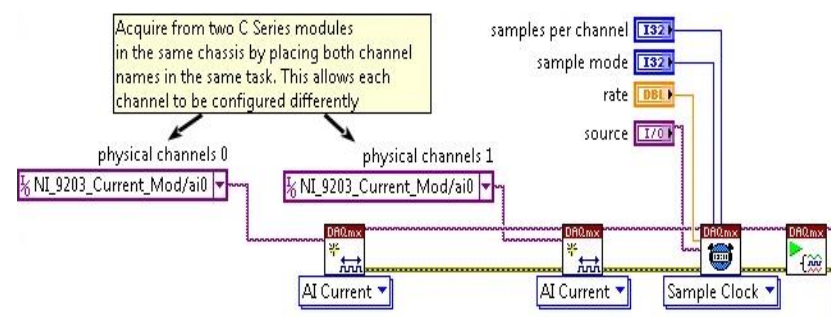

Slika 7: Primer koda za sinhronizaciju mernih kartica

Kao što je već navedeno u predhodnom tekstu, moduli se povezuju $\mathrm{u}$ isti task, prosleđuje im se isti takt za sinhronizaciju koji dobijaju od šasije konfigurisanjem DAQmx Timing funkcije, nakon čega započinju merenje u isto vreme kada funkcija DAQmx Start Task postane aktivna.

Kako bi se pokazalo da je sistem sinhronizovan, korišćenjem aplikacije napravljen je snimak koji dokazuje sinhrono očitavanje kanala, videti sl. 8 .

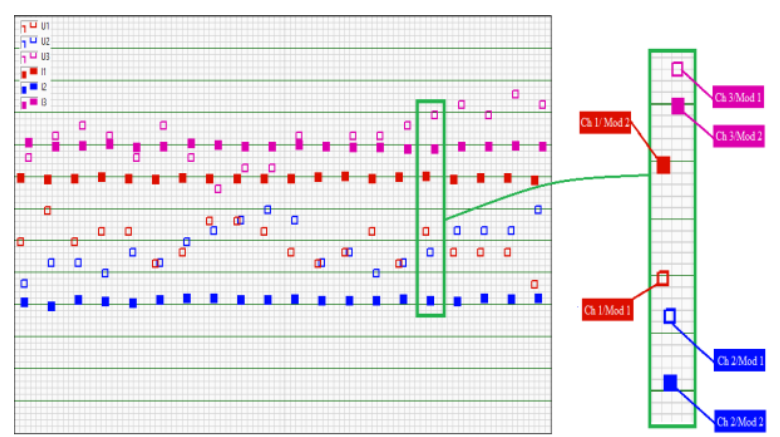

Slika 8: Pregled trenutaka odbirkovanja signala svakog kanala

Na slici praznim kvadratima obeleženi su odbirci signala prvog modula koji snimaju naponske signale. Sa popunjenim kvadratima obeleženi su odbirci signala drugog modula koji snimaju strujne signale. $\mathrm{Na}$ osnovu priložene slike zaključuje se da kanali, parovi signala iste boje, imaju istovremeno očitavanje.

\section{MERENJE SNAGE}

Funkcija za merenje snage implementirana je u postojeću aplikaciju $M A S$. Funkcija koristi neobrađene signale koji dolaze iz memorijskog bafera. Prilikom izrade, zahtev korisnika je bio da projektovani sistem treba da zadovoljava merenje snage samo za frekvenciju od $50 \mathrm{~Hz}$, koja pokriva većinu potreba merenja.

Navedena funkcija računa snagu na osnovu trenutne vrednosti struje i trenutne vrednosti napona. Pošto je frekvencija poznata, od tih trenutnih vrednosti signala može se proračunati efektivna vrednost signala sa ugrađenom funkcijom Averaged DC-RMS, videti sl. 9.

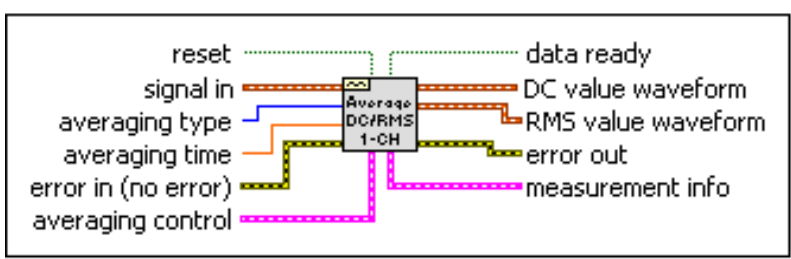

Slika 9: LabVIEW funkcija za proračun efektivne vrednosti signala

U funkciju Averaged DC-RMS dovodi se određeni ulazni signal. Kao parametar se prosleđuje vreme merenja, koji označava dužinu intervala signala za koju će funkcija proračunavati efektivne vrednosti signala. U ovom slučaju interval u kojem se vrši proračun je $t=0,02 \mathrm{~s}$.

Nakon proračuna efektivne vrednosti, pristupa se merenju fazne razlike između signala. U prethodnom poglavlju prikazano je objašnjenje sinhronizacije kartica i način očitavanja kanala. Zaključeno je da ne postoji fazna razlika u očitavanju između parova kanala. Funkcija koja obezbeđuje ovakvo merenje naziva se Single Tone Information koja je u okviru palete za obradu signala. Prikaz izgleda funkcije je na $s l$. 10 . 


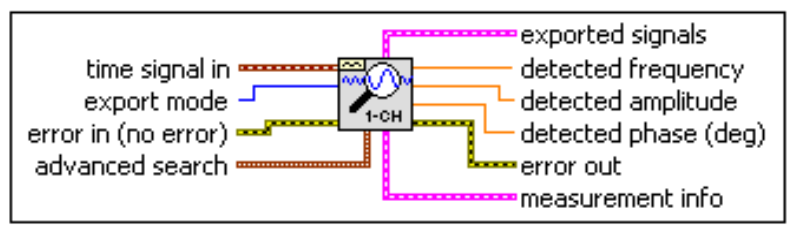

Slika 10: LabVIEW funkcija za proračun faznog pomeraja signala

Navedena funkcija kao izlaz daje veliki broj informacija o signalu koji je doveden na njen ulaz. Korišćene su:

- Merenje frekvencije

- Merenje amplitude

- Merenje faze u stepenima

Korišćenjem prethodno navedenih funkcija izračunava se snaga sistema:

$$
S=U_{e f 1} \times I_{e f 1}+U_{e f 2} \times I_{e f 2}+U_{e f 3} \times I_{e f 3} \text { (1) }
$$

dok se uvođenjem vrednosti međufazne razlike između napona i struja izračunavaju aktivna i reaktivna snaga sistema kao:

$$
\begin{aligned}
P & =U_{e f 1} \times I_{e f 1} \times \cos \varphi+U_{e f 2} \times I_{e f 2} \times \cos \varphi \\
& +U_{e f 3} \times I_{e f 3} \times \cos \varphi(2) \\
Q & =U_{e f 1} \times I_{e f 1} \times \sin \varphi+U_{e f 2} \times I_{e f 2} \times \sin \varphi \\
& +U_{e f 3} \times I_{e f 3} \times \sin \varphi
\end{aligned}
$$

\section{KOMPENZACIJA KAŠNJENJA}

Analizirano je kašnjenje u svakom mernom kanalu. Utvrđeno je da prilagodnik signala koji preslikava ulazni naponski signal na svoj izlaz, u opsegu od $\pm 20 \mathrm{~mA}$, unosi određenu stalnu razliku u fazi između ulaznog i izlaznog siglala. Na sl. 11. prikazani su signali snimljeni osciloskopom FLUKE 190-102.

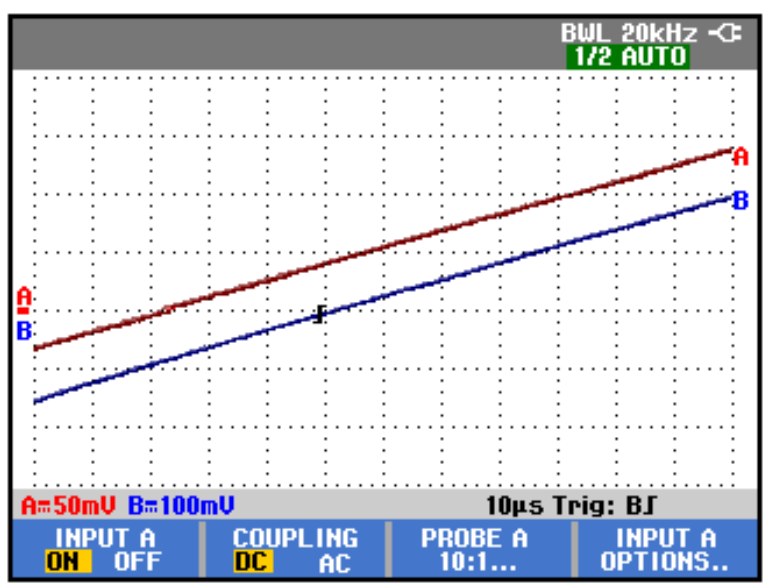

Slika 11: Snimak fazne razlike signala

Prvi signal, obeležen sa $A$, predstavlja mereni signal koji se dovodi na ulaz prilagodnika signala. Drugi signal, obeležen sa $B$, predstavlja signal na njegovom izlazu. Pre merenja svaki od signala izjednačen je po amplitudi i postavljen je da bude simetričan u odnosu na osu koja je odabrana za referentnu.
Izmerena je stalna vrednost kašnjenja $\Delta t=30 \mu \mathrm{s}$.

Za potrebe kompenzacije prethodno utvrđenog kašnenja projektovano je odgovarajuće softversko rešenje. Primenjeno rešenje ogleda se $u$ tome što se vrednosti strujnih signala ukupno vremenski pomeraju u odnosu na naponske signale za vrednost izmerenog kašnjenja. Rezultat je proračun tačnog faznog stava između vektora napona i struje u svakoj fazi.

U kanalima za merenje struje kompenzacija u kašnjenju nije bila potrebna jer je utvrđeno kašnjenje koje je manje od $0,2 \mu \mathrm{s}$

\section{VERIFIKACIJA}

Softverski realizovana funkcija merenja snage sa uključenom kompenzacijom faznog kašnjenja implementirana je u aplikaciju $M A S$.

Verifikacija ispravnosti i tačnosti merenja funkcije izvršena je upotrebom preciznog analizatora snage opisanog u 3.4 koji je sa $M A S$ bio istovremeno priključen na izor trofaznog napona i struja koji je opisan 3.3.

Merenjem je utvrđeno da je razlika u vrednosti izmerene trenutne snage bez kompenzacije faznog kašnjenja i sa uključenom kompenzacijom faznog kašnjenja veća od $1 \%$.

\section{ZAKLJUČAK}

U radu je prikazana uspešna praktična primena softverskog alata u realizaciji merenja snage trofaznog sistema pomoću merno-akvizicionog sistema opšte namene.

Svaki korak u projektovanju softverskog rešenja zasnovan je na merenjima. Konačni rezultat prikazanog softverskog rešenja verifikovan je merenjem.

Softversko rešenje je uspešno praktično primenjeno.

\section{LITERATURA}

[1] https://www.ni.com/pdf/manuals/372838e.pdf

[2] https://www.ni.com/pdf/manuals/374070a_02.pdf

[3] https://www.fluke.com/en-us/product/electricaltesting/portable-oscilloscopes/190-series-ii/fluke-190ii-190-102\#specs-tab

[4] RETOMTM-51 User Manual

[5] https://www.zes.com/en/Products/DiscontinuedProducts/Energy-and-Power-Meters/LMG640

\section{Kratka biografija:}

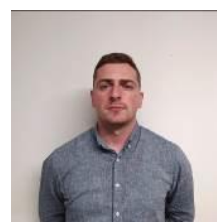

Aleksandar Dimitrijević rođen je u Surdulici 1997. god. Bachelor rad na Fakultetu tehničkih nauka iz oblasti Elektrotehnike i računarstva - Merenje i regulacija odbranio je 2020. god. kontakt: adimitrijevic22@gmail.com 